\title{
Sevoflurane-induced memory impairment in the postnatal developing mouse brain
}

\author{
ZHIJUN LU ${ }^{1}$, JIHUI SUN $^{1}, \mathrm{YICHUN} \mathrm{XIN}^{1}, \mathrm{KEN} \mathrm{CHEN}^{1}, \mathrm{WEN} \mathrm{DING}^{1}$ and YUJA WANG ${ }^{2}$ \\ ${ }^{1}$ Department of Anesthesia, Rui Jin Hospital Luwan Branch, Shanghai Jiao Tong University School of Medicine, \\ Shanghai 200020; ${ }^{2}$ Intensive Care Unit, Shanghai Jing'an District Shibei Hospital, Shanghai 200443, P.R. China
}

Received March 31, 2016; Accepted March 6, 2017

DOI: $10.3892 /$ etm.2018.5950

\begin{abstract}
The aim of the present study was to confirm that sevoflurane induces memory impairment in the postnatal developing mouse brain and determine its mechanism of action. C57BL/6 mice 7 days old were randomly assigned into a $2.6 \%$ sevoflurane $(n=68)$, a $1.3 \%$ sevoflurane $(n=68)$ and a control $(n=38)$ group. Blood gas analysis was performed to evaluate hypoxia and respiratory depression during anesthesia in 78 mice. Measurements for expression of caspase-3 by immunohistochemistry, cleavage of poly adenosine diphosphate-ribose polymerase (PARP) by western blotting, as well as levels of brain-derived neurotrophic factor (BDNF), tyrosine kinase receptor type 2 (Ntrk2), pro-BDNF, p75 neurotrophin receptor (p75NTR) and protein kinase $B(\mathrm{PKB} / \mathrm{Akt})$ by enzyme-linked immunosorbent assay were performed in the hippocampus of 12 mice from each group. A total of 60 mice underwent the Morris water maze (MWM) test. Results from the MWM test indicated that the time spent in the northwest quadrant and platform site crossovers by mice in the 2.6 and $1.3 \%$ sevoflurane groups was significantly lower than that of the control group. Meanwhile, levels of caspase-3 and cleaved PARP in the 2.6 and $1.3 \%$ sevoflurane groups were significantly higher than that in the control group. Levels of pro-BDNF and p75NTR were significantly increased and the level of PKB/Akt was significantly decreased following exposure to $2.6 \%$ sevoflurane. Finally, the memory of postnatal mice was impaired by sevoflurane, this was determined using a MWM test. Therefore, the results of the current study suggest that caspase-3 induced cleavage of PARP, as well as pro-BDNF, p75NTR and PKB/Akt may be important in sevoflurane-induced memory impairment in the postnatal developing mouse brain.
\end{abstract}

Correspondence to: Dr Yujia Wang, Intensive Care Unit, Shanghai Jing'an District Shibei Hospital, 4500 Gonghexin Road, Shanghai 200443, P.R. China

E-mail: yujiawangwww@hotmail.com

Key words: sevoflurane, memory impairment, postnatal mouse, hippocampus

\section{Introduction}

Sevoflurane is a widely used inhalational anesthetic agent that is commonly used in cesarean sections (1) and in operations on infants and young children $(2,3)$. However, the neurotoxic effect of sevoflurane can damage the developing brain and thereby influence long-term learning and memory in animals (4-6). Thus, the use of sevoflurane in cesarean delivery or operation for infants and young children may be detrimental to the brain development of infants and children, and influence the memory and cognitive function during childhood. Currently, sevoflurane-induced memory impairment is a method of evaluating sevoflurane-induced damage in the developing brain $(5,6)$. However, the mechanism of sevoflurane-induced memory impairment remains unclear.

Previous studies have demonstrated that $6 \mathrm{~h}$ sevoflurane exposure may significantly increase the expression of caspase-3, which is a marker of neural apoptosis (7), in the hippocampi of postnatal rats (8) and neonatal mice (9). Furthermore, it has been determined that neural apoptosis in the hippocampus is associated with impaired memory and cognitive function $(10,11)$. However, to the best of our knowledge, there have been no studies identifying the role of caspase-3 in sevoflurane-induced memory impairment in the developing brain. Poly adenosine diphosphate-ribose polymerase (PARP), a substrate of caspase-3, is associated with long-term memory (12-14). Thus, it was suggested that PARP may be cleaved by overexpressed caspase- 3 in the sevoflurane-treated developing brain. In addition, brain-derived neurotrophic factor (BDNF), cleaved from a precursor of BDNF (pro-BDNF) and tyrosine kinase receptor type 2 (Ntrk2, also known as TrkB), both important in the survival and growth of neurons $(15,16)$, are also correlated with learning and memory (17). Furthermore, it has been reported that the p75 neurotrophin receptor (p75NTR) has marked effects on hippocampal function: Knockout of p75NTR enhanced spatial memory in adult mice (18). Thus, p75NTR may also be involved in sevoflurane-induced memory impairment in the developing brain. Furthermore, protein kinase $\mathrm{B}$ ( $\mathrm{PKB} / \mathrm{Akt}$, a serine/threonine kinase) has been found to serve a role in numerous pathways that are associated with memory $(19,20)$.

Emergency cesarean sections are performed on pregnant women in their third trimester gestation when required and 
sevoflurane is often used as an anesthetic during this procedure. However, the use of sevoflurane during a cesarean section may affect brain development and cause memory impairment in postnatal infants. Thus, 7-day-old mice, equivalent to a human third trimester gestation (21), were used in the current study to investigate the effect of sevoflurane on the memory of postnatal infants. In the present study, levels of caspase-3, cleaved PARP, BDNF, Ntrk2, pro-BDNF, p75NTR and PKB/Akt proteins were investigated in the hippocampi of postnatal mice following $6 \mathrm{~h}$ sevoflurane exposure to identify the mechanism of sevoflurane-induced memory impairment in the developing brain. The memory of these postnatal mice was assessed using a Morris water maze (MWM) test at weeks 4 and 12 following sevoflurane exposure to confirm the effect of sevoflurane on memory impairment in postnatal mice.

\section{Materials and methods}

Animal model. All experiments were performed according to the guidelines of the Guide for the Care and Use of Laboratory Animals (22) and were approved by the Institutional Animal Care and Use Committee of Ruijin Hospital Affiliated to Shanghai Jiaotong University (Shanghai, China). A total of 174 C57BL/6 mice (sex ratio, 1:1), were provided by the Model Animal Research Center of Nanjing University (Nanjing, China). They were housed in polypropylene cages (5 or 6 animals per cage) and kept at a $12 \mathrm{~h}$ light-dark cycle at room temperature $\left(21-24^{\circ} \mathrm{C}\right)$ in $55 \%$ humidity for 7 days prior to testing. All animals had free access to food and water.

Experimental protocols. There were two experimental protocols used based on the sevoflurane concentration used in previous studies $(23,24)$ and 1.3 and $2.6 \%$ sevoflurane was used in the present study. For protocol one, 36 mice were randomly assigned into 3 groups with 12 mice in each group: The 2.6 and $1.3 \%$ sevoflurane groups and the control group (exposed to $30 \% \mathrm{O}_{2}$ ). Following exposure to sevoflurane or $\mathrm{O}_{2}$ for $6 \mathrm{~h}$, the mice from all 3 groups were sacrificed by intraperitoneal injection of $1.5 \%$ pentobarbital sodium (375 mg/kg) (Dalian Idery Biotechnology Co., Ltd., Dalian, China). Hippocampal tissue samples from these mice were collected to measure the expression of caspase-3 using immunohistochemistry, the cleavage of PARP by western blotting, and levels of BDNF, Ntrk2, pro-BDNF, p75NTR and PKB/Akt by ELISA. To evaluate whether hypoxia and respiratory depression occurred in mice during anesthesia, blood gas analysis was performed in another 78 mice, which were randomly assigned into 3 groups: $2.6 \%$ sevoflurane $(n=36)$, $1.3 \%$ sevoflurane $(n=36)$ and control $(n=6)$ groups. The mice in the 1.3 and $2.6 \%$ sevoflurane groups were divided into subgroups based on the length of time they were exposed to sevoflurane $(1,2,3,4,5$ and $6 \mathrm{~h})$, with 6 mice in each subgroup.

For protocol two, a total of 60 mice were randomly assigned into 3 groups with 20 mice in each group: 2.6, 1.3\% sevoflurane and control groups. Following exposure to sevoflurane for 4 weeks, the MWM test was performed in half of the mice in each group. The MWM test was conducted on the remaining mice at week 12 .
Sevoflurane exposure. As stated in a previous study (25), animals were placed in a temperature-controlled $\left(37-38^{\circ} \mathrm{C}\right)$ transparent anesthetic chamber that was connected to an anesthetic gas monitor (Datex-Ohmeda S/5, Datex-Ohmeda; GE Healthcare Bio-Sciences, Pittsburgh, PA, USA). For mice in the 1.3 and $2.6 \%$ sevoflurane groups, mixed gas $(5 \%$ sevoflurane and $30 \% \mathrm{O}_{2}$ ) was pre-aerated at a flow rate of $10 \mathrm{l} / \mathrm{min}$ until the concentration of sevoflurane reached $5 \%$ in the chamber and prior to placing mice in the chamber. Subsequently, these mice were placed into the chamber immediately. Following maintenance of $5 \%$ sevoflurane for $30 \mathrm{sec}$, mice were exposed to 1.3 or $2.6 \%$ sevoflurane for the indicated time periods (1-6 h), during which $30 \% \mathrm{O}_{2}$ was continually gassed into the chamber at a flow rate of $3 \mathrm{l} / \mathrm{min}$. For mice in the control group, $30 \%$ $\mathrm{O}_{2}$ alone was aerated into the chamber for $6 \mathrm{~h}$, with a flow rate of $3 \mathrm{l} / \mathrm{min}$.

Blood gas analysis. The mice were anesthetized by intraperitoneal injection of $1.5 \%$ sodium pentobarbital $(50 \mathrm{mg} / \mathrm{kg})$. Then blood samples $(0.2 \mathrm{ml})$ were obtained from the left ventricle by cardiac puncture, after which the mice were sacrificed by intraperitoneal injection of $1.5 \%$ sodium pentobarbital $(375 \mathrm{mg} / \mathrm{kg}$ ). The partial pressure of oxygen $\left(\mathrm{PaO}_{2}\right)$, partial pressure of carbon dioxide $\left(\mathrm{PaCO}_{2}\right)$ and arterial oxygen saturation $\left(\mathrm{SaO}_{2}\right)$ were detected using a portable blood gas analyzer (OPTI Medical Systems Inc., Roswell, GA, USA).

Tissue sample collection. Following sevoflurane exposure, all the mice were sacrificed by intraperitoneal injection of $1.5 \%$ pentobarbital sodium $(375 \mathrm{mg} / \mathrm{kg})$. The brain was then rapidly removed and the complete hippocampus was dissected. Hippocampal tissue samples were stored at $-80^{\circ} \mathrm{C}$ prior to use in laboratory experiments.

Immunohistochemistry. The hippocampal tissues were fixed overnight in $4 \%$ paraformaldehyde at $4^{\circ} \mathrm{C}$. The hippocampal slices $(5-\mu \mathrm{m}$-thick) were subsequently prepared using a vibrating tissue slicer (Campden Instruments, Ltd., Loughborough, UK). Immunohistochemical staining was performed as previously described $(26,27)$. Briefly, slices were incubated with hydrogen peroxide in methanol to block endogenous peroxidase activity and $10 \%$ normal goat serum (cat. no. C0265; Beyotime Institute of Biotechnology, Haimen, China) to reduce non-specific antibody binding prior to immunohistochemical staining. Slices were then incubated with a rabbit anti-caspase-3 antibody (1:200; cat. no. AC033; Beyotime Institute of Biotechnology) at $4^{\circ} \mathrm{C}$ for $12 \mathrm{~h}$, followed by three washes with PBS. Subsequently, these slices were incubated with secondary antibody (1:4,000; cat. no. A0562; biotinylated goat anti-rabbit antibody; Beyotime Institute of Biotechnology) for $30 \mathrm{~min}$ at $37^{\circ} \mathrm{C}$. Following washing with PBS, immunoreactivity was visualized using the streptavidin-peroxidase complex and 3,3'-diaminobenzidine (both from Beyotime Institute of Biotechnology). A DM5000B light microscope (Leica Microsystems GmBH, Wetzlar, Germany) was used to observe and collect images. The image analysis software Image Pro Plus version 4.0 (Media Cybernetics, Inc., Rockville, MD, USA) was used to count the number of caspase-3 positive cells. 
Western blotting. The preparation of hippocampus protein extraction was performed as previously described $(28,29)$. Total proteins were extracted with radioimmunoprecipitation assay buffer [1\% Triton X-100, $50 \mathrm{mM}$ Tris, (pH 7.4), $150 \mathrm{mM}$ $\mathrm{NaCl}, \mathrm{M}, 0.1 \%$ sodium dodecyl sulfate (SDS), 1 mM EDTA and $1 \%$ sodium deoxycholate]. Following $13,000 \mathrm{x}$ g centrifugation at $4^{\circ} \mathrm{C}$ for $20 \mathrm{~min}$, the supernatant was used for western blotting $(30,31)$. The BCA method was used to assay protein concentrations. In brief, hippocampal tissue proteins were separated by $10 \%$ SDS polyacrylamide gel electrophoresis and then electrotransferred to nitrocellulose membranes. The membranes were blocked with $5 \%$ non-fat powdered milk for $1 \mathrm{~h}$ at $25^{\circ} \mathrm{C}$. The proteins were probed with rabbit anti-PARP antibodies (1:200, cat. no. AP102) or rat anti-GAPDH antibodies (1:5,000, cat. no. AG019) overnight at $4^{\circ} \mathrm{C}$. Then, goat anti-rabbit (1:4,000; cat. no. A0208) or goat anti-rat (1:4,000; cat. no. A0192) horseradish peroxidase-conjugated secondary antibodies were used for $2 \mathrm{~h}$ incubation at room temperature (all from Beyotime Institute of Biotechnology). Proteins were visualized by an enhanced chemiluminescence method and analyzed with the Dolphin-Doc Plus Gel Documentation system (version 1141002; Wealtec Corp., Sparks, NV, USA). This procedure was repeated twice for all 3 groups. The relative level of PARP was presented as the band intensity and normalized to the corresponding band intensities of GAPDH.

ELISA. The method of hippocampus protein extraction mentioned above was also used for ELISA. The levels of BDNF, Ntrk2, pro-BDNF, p75NTR and PKB/Akt were measured using an ELISA kit (cat. no. EK0312; Wuhan Boster Bio-Engineering Co., Ltd., Wuhan, China) according to the manufacturer's instructions. Briefly, protein samples were added to the enzyme label plate and incubated for $1.5 \mathrm{~h}$ at $37^{\circ} \mathrm{C}$. Next, the biotin-labeled antibodies were added for $1 \mathrm{~h}$ incubation at $37^{\circ} \mathrm{C}$. Following washing, $30 \mathrm{~min}$ incubation with avidin peroxidase complex was conducted at $37^{\circ} \mathrm{C}$. Color was developed using 3,3',5,5'-tetramethylbenzidine following $20 \mathrm{~min}$ incubation at $37^{\circ} \mathrm{C}$. Following reaction termination with a 'stop' solution, the products were measured at $450 \mathrm{~nm}$ using a microplate spectrophotometer (Spectramax 190; Molecular Devices LLC, Sunnyvale, CA, USA). All samples were assayed in duplicate and the readings were normalized to the amount of standard protein.

Behavioral studies. Prior to the MWM test, mice received 2 min of touch for 5 days to avoid the fear to touch during the test. The MWM test was performed as previously described $(32,33)$, with minor modifications. The round pool (diameter, $122 \mathrm{~cm}$ ) was filled with warm water, made opaque by the addition of titanium dioxide and an escape platform was placed in the northwest quadrant and hidden $0.5 \mathrm{~cm}$ below the surface of the water. The MWM test was performed on 7 consecutive days ( 6 days for training and 1 day for the probe test). Briefly, mice received 4 training sessions daily for 6 consecutive days. Each trial began from a different point and ended when the mice found the platform. The time from beginning to end was considered to be the time of escape latency. If mice could not find the platform within $90 \mathrm{sec}$, the time of escape latency was recorded as $90 \mathrm{sec}$. If mice found the platform within $90 \mathrm{sec}$, the real time from beginning to end was recorded as the time of escape latency. The swim rate during training was also recorded. On day 7 , the probe test was performed by allowing the mice to swim for $60 \mathrm{sec}$ in the absence of the platform. During $60 \mathrm{sec}$ swimming, the time spent in the northwest quadrant and platform site crossovers was recorded and analyzed using the MWM JLBehv-FCS video analysis system (DigBehv-MG; Shanghai Jiliang Software Technology Co., Ltd., Shanghai, China).

Statistical analysis. All data are presented as the mean \pm standard error of the mean. A repeated measures analysis of variance (ANOVA) was used to measure the differences within groups over time. Meanwhile, one-way ANOVA was applied for comparison among groups (2.6, 1.3\% sevoflurane and control groups), followed by Student Newman-Keuls post hoc test. The correlation between the swim rate and time of escape latency was identified using the Pearson Correlation coefficient. For all the analysis, $\mathrm{P}<0.05$ was used to indicate a statistically significant difference. Additionally, SPSS 11.5 (SPSS, Inc., Chicago, IL, USA) was used for the analysis of the present study.

\section{Results}

Results of blood gas analysis. The $\mathrm{PaO}_{2}, \mathrm{PaCO}_{2}$ and $\mathrm{SaO}_{2}$ values remained stable in the 2.6 and $1.3 \%$ sevoflurane and control groups following treatment. There were no significant differences identified among groups and the $\mathrm{PaO}_{2}, \mathrm{PaCO}_{2}$ and $\mathrm{SaO}_{2}$ values did not notably change with increasing time periods of sevoflurane exposure (Table I).

Sevoflurane increases caspase-3 expression. Significantly more caspase-3 positive cells were found in the 2.6 and $1.3 \%$ sevoflurane groups compared with the control group $(\mathrm{P}<0.05)$. Meanwhile, the number of positive cells in the $2.6 \%$ sevoflurane group was significantly higher than that of the $1.3 \%$ sevoflurane group $(\mathrm{P}<0.05$; Fig. 1).

Sevoflurane promotes the cleavage of PARP. Relative levels of cleaved PARP in the $2.6 \%(1.552 \pm 0.178)$ and $1.3 \%$ $(1.376 \pm 0.157)$ sevoflurane groups were significantly increased following sevoflurane exposure compared with the control group $(0.729 \pm 0.106 ; \mathrm{P}<0.001)$. However, there was no significant difference in the level of cleaved PARP $(\mathrm{P}>0.05)$ detected in the 2.6 and $1.3 \%$ sevoflurane groups ( $P>0.05$; Fig. 2).

Effect of sevoflurane on BDNF, Pro-BDNF, TrkB, Akt/PKB and $p 75 N T R$. According to ELISA, 2.6\% sevoflurane significantly increased the expression of Pro-BDNF compared with the control group (2.6\% sevoflurane group, 3,146.32 \pm 47.96 vs. control group, 2,817.17 $\pm 47.96 ; \mathrm{P}<0.05)$. Furthermore, the level of Akt/PKB was significantly decreased following $6 \mathrm{~h}$ exposure to $2.6 \%$ sevoflurane, compared with the control

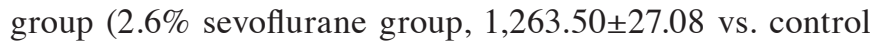
group, 1,557.35 $\pm 59.87 ; \mathrm{P}<0.05)$. In addition, levels of p75NTR in the $2.6 \%(119.40 \pm 2.58)$ and $1.3 \%(119.04 \pm 1.45)$ sevoflurane groups were significantly higher than those in the control group $(108.34 \pm 3.77 ; \mathrm{P}<0.05)$. However, there were no significant differences in the levels of BDNF and TrkB $(\mathrm{P}>0.05)$ among groups (Table II). 
Table I. Results of blood gas analysis during sevoflurane exposure.

\begin{tabular}{|c|c|c|c|}
\hline Time and concentration of sevoflurane exposure & $\mathrm{PaO}_{2}(\mathrm{mmHg})$ & $\mathrm{PaCO}_{2}(\mathrm{mmHg})$ & $\mathrm{SaO}_{2}$ \\
\hline Before exposure (control group) & $105 \pm 2$ & $21.8 \pm 0.8$ & $99.0 \pm 0.3$ \\
\hline $1 \mathrm{~h}$ of $2.6 \%$ & $103 \pm 2$ & $23.6 \pm 0.7$ & $98.3 \pm 0.4$ \\
\hline $2 \mathrm{~h}$ of $2.6 \%$ & $98 \pm 4$ & $23.0 \pm 0.9$ & $97.4 \pm 0.6$ \\
\hline $3 \mathrm{~h}$ of $2.6 \%$ & $100 \pm 2$ & $23.6 \pm 1.2$ & $98.0 \pm 0.5$ \\
\hline $4 \mathrm{~h}$ of $2.6 \%$ & $99 \pm 2$ & $22.5 \pm 0.9$ & $97.4 \pm 0.9$ \\
\hline $5 \mathrm{~h}$ of $2.6 \%$ & $103 \pm 3$ & $22.0 \pm 0.9$ & $98.2 \pm 0.4$ \\
\hline $6 \mathrm{~h}$ of $2.6 \%$ & $100 \pm 2$ & $23.0 \pm 1.0$ & $99.0 \pm 0.5$ \\
\hline $1 \mathrm{~h}$ of $1.3 \%$ & $103 \pm 2$ & $23.9 \pm 0.7$ & $98.1 \pm 0.4$ \\
\hline $2 \mathrm{~h}$ of $1.3 \%$ & $99 \pm 1$ & $23.3 \pm 0.9$ & $97.2 \pm 0.6$ \\
\hline $3 \mathrm{~h}$ of $1.3 \%$ & $99 \pm 2$ & $24.1 \pm 1.5$ & $97.9 \pm 0.5$ \\
\hline $4 \mathrm{~h}$ of $1.3 \%$ & $102 \pm 3$ & $23.6 \pm 0.9$ & $98.6 \pm 0.5$ \\
\hline $5 \mathrm{~h}$ of $1.3 \%$ & $100 \pm 3$ & $23.6 \pm 0.9$ & $97.6 \pm 0.4$ \\
\hline $6 \mathrm{~h}$ of $1.3 \%$ & $99 \pm 2$ & $23.0 \pm 1.1$ & $98.1 \pm 0.5$ \\
\hline
\end{tabular}

A repeated measures ANOVA was used to assess the differences of data at different time points. The one-way ANOVA method was applied for comparison among groups. No significant differences were observed among the data at different time points and among the three groups. Data are presented as the mean \pm standard error of the mean. $\mathrm{n}=6$. $\mathrm{PaO}_{2}$, partial pressure of oxygen; $\mathrm{PaCO}_{2}$, partial pressure of carbon dioxide; $\mathrm{SaO}$, arterial oxygen saturation. ANOVA, analysis of variance.
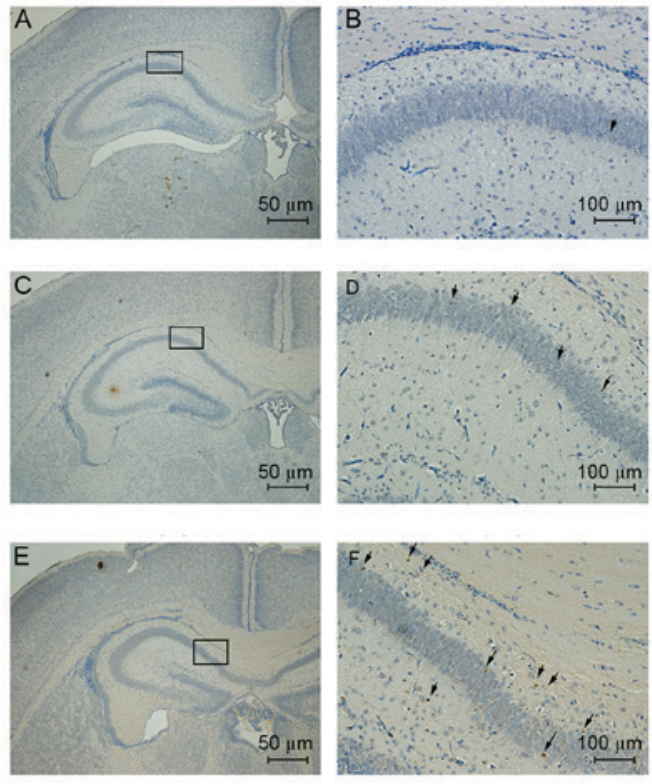

G

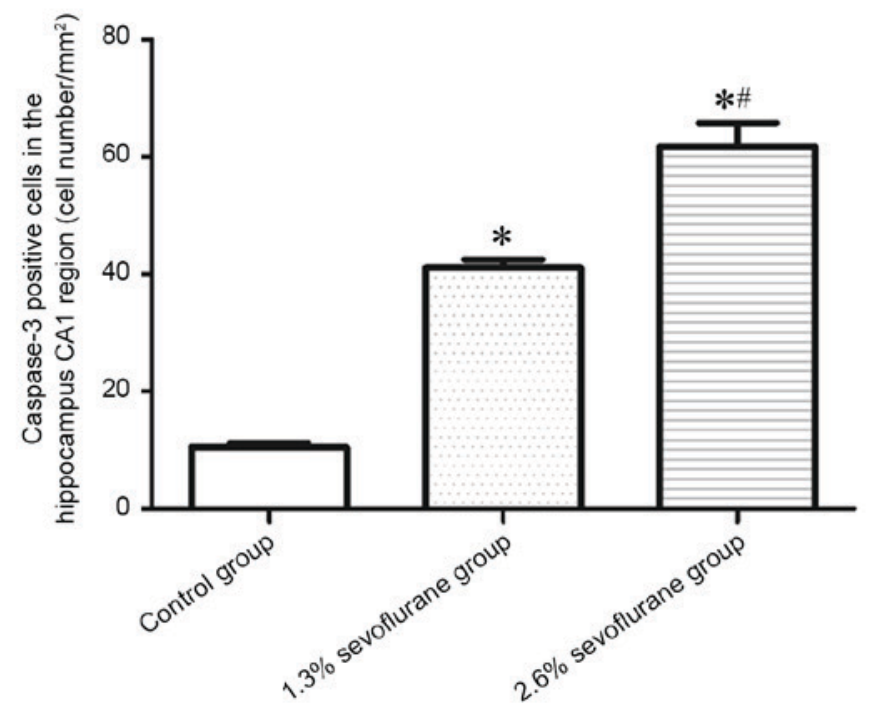

Figure 1. Expression of caspase-3 in hippocampus cells. (A-F) Images of immunohistochemical staining. (A and B) Control; (C and D) $1.3 \%$ sevoflurane and (E and F) $2.6 \%$ sevoflurane groups. A, C and E, magnification, $\mathrm{x} 4$, scale bar, $50 \mu \mathrm{m}$; B, D and F: magnification, $\mathrm{x} 20$, scale bar, $100 \mu \mathrm{m}$. The boxes in A, C and E indicate the area of caspase- 3 positive cells, and parts B, D and $\mathrm{F}$ are these boxes at a higher magnification. The arrows in $\mathrm{B}, \mathrm{D}$ and $\mathrm{F}$ indicate caspase-3 positive cells. (G) The numbers of caspase-3 positive cells in the hippocampal CA1 region in each group; ${ }^{*} \mathrm{P}<0.05$, compared with the control group; ${ }^{*} \mathrm{P}<0.05$, compared with the $1.3 \%$ sevoflurane group.

Effect of sevoflurane on mouse memory. As presented in Table III, the time of escape latency significantly decreased as duration time increased in each group during 6 days training at weeks 4 and 12 following sevoflurane exposure $(\mathrm{P}<0.05)$. Moreover, the time of escape latency on days 4, 5 and 6 in the 2.6 and $1.3 \%$ sevoflurane groups were all significantly higher than that of the control group 4 weeks following sevoflurane exposure $(\mathrm{P}<0.05)$. Meanwhile, no significant difference in time of escape latency on days 1, 2 and 3 was observed between the 2.6 and $1.3 \%$ sevoflurane groups 4 weeks following sevoflurane exposure. However, only the time of escape latency on day 6 of training in the $2.6 \%$ sevoflurane group was significantly higher than that of the control group 12 weeks following sevoflurane exposure $(\mathrm{P}<0.05)$. Furthermore, no significant difference among groups was revealed in the other times of escape latency $(\mathrm{P}>0.05)$ and there was no significant correlation between the time of escape latency and swim rate $(r>0$; $\mathrm{P}>0.05$ ) observed in the present study. 
Table II. Levels of BDNF, Pro-BDNF, TrkB, Akt/PKB and p75NTR in the hippocampal tissues in each group.

\begin{tabular}{lccccc}
\hline Group & BDNF $(\mathrm{pg} / \mathrm{ml})$ & Pro-BDNF $(\mathrm{pg} / \mathrm{ml})$ & TrkB $(\mathrm{pg} / \mathrm{ml})$ & Akt/PKB $(\mathrm{pg} / \mathrm{ml})$ & $\mathrm{p} 75 N T R(\mathrm{pg} / \mathrm{ml})$ \\
\hline 2.6\% sevoflurane & $1,198.69 \pm 31.12$ & $3,146.32 \pm 47.96^{\mathrm{a}}$ & $711.39 \pm 20.37$ & $1,263.50 \pm 27.08^{\mathrm{a}}$ & $119.40 \pm 2.58^{\mathrm{a}}$ \\
1.3\% sevoflurane & $1,188.00 \pm 18.02$ & $2,938.97 \pm 113.63$ & $759.39 \pm 13.78$ & $1,459.45 \pm 23.00$ & $119.04 \pm 1.45^{\mathrm{a}}$ \\
Control & $1,129.50 \pm 34.15$ & $2,817.17 \pm 47.96$ & $717.60 \pm 18.89$ & $1,557.35 \pm 59.87$ & $108.34 \pm 3.77$ \\
P-value $^{\mathrm{b}}$ & 0.128 & 0.039 & 0.139 & $<0.001$ & 0.013 \\
\hline
\end{tabular}

${ }^{\mathrm{a}} \mathrm{P}<0.05$ vs. the control using Student Newman-Keuls post hoc test. ${ }^{\mathrm{b}} \mathrm{P}$-value was calculated from $2.6 \%, 1.3 \%$ sevoflurane and control groups by the one-way analysis of variance method. Data are presented as the mean \pm standard error of the mean. $n=12$. BDNF, brain-derived neurotrophic factor; TrkB, tyrosine kinase receptor type 2; Akt/PKB, protein kinase B; pro-BDNF, a precursor of BDNF; p75NTR, p75 neurotrophin receptor; $\mathrm{PKB} / \mathrm{Akt}$, protein kinase $\mathrm{B}$.

A

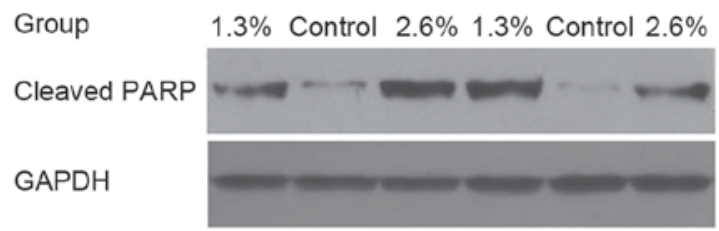

B
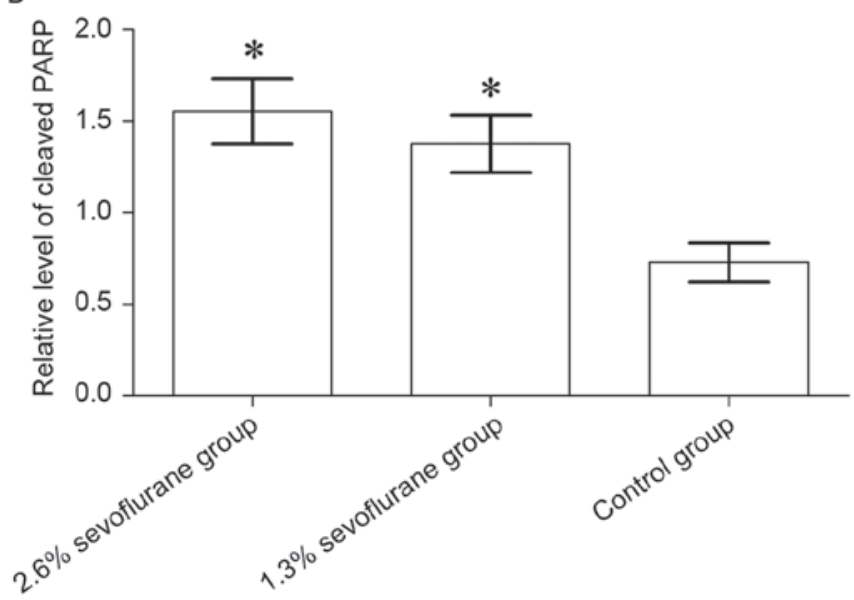

Figure 2. Levels of cleaved PARP in the hippocampus tissue in each group. (A) Images of western blotting; (B) Relative levels of cleaved PARP in each group. ${ }^{*} \mathrm{P}<0.05$, compared with the control group. PARP, poly adenosine diphosphate-ribose polymerase.

The results of the probe test revealed that the time spent in the northwest quadrant (week $4: 2.6 \%$ sevoflurane group, $0.04 \pm 0.03 \mathrm{sec} ; 1.3 \%$ sevoflurane group, $0.19 \pm 0.09 \mathrm{sec}$; control group, $0.88 \pm 0.21 \mathrm{sec}$; and week 12: $2.6 \%$ sevoflurane group, $0.23 \pm 0.11 \mathrm{sec} ; 1.3 \%$ sevoflurane group, $1.00 \pm 0.27 \mathrm{sec}$ and control group, $15.32 \pm 3.62 \mathrm{sec}$ ) and number of platform site crossovers (week 4: $2.6 \%$ sevoflurane group, 0.25 \pm 0.16 ; $1.3 \%$ sevoflurane group, $0.63 \pm 0.32$; control group, $2.38 \pm 0.65$; and week 12: $2.6 \%$ sevoflurane group, $0.67 \pm 0.33 ; 1.3 \%$ sevoflurane group, 2.63 \pm 0.71 ; control group, $4.67 \pm 1.18$ ) in the 2.6 and $1.3 \%$ sevoflurane groups were significantly lower compared with the control group $(\mathrm{P}<0.05)$ at weeks 4 and 12 after sevoflurane exposure. Moreover, platform site crossovers were significantly decreased following $6 \mathrm{~h}$ exposure to $2.6 \%$ sevoflurane compared with the $1.3 \%$ sevoflurane group 12 weeks after sevoflurane exposure $(\mathrm{P}<0.05$; Table IV).

\section{Discussion}

In the present study, the results of the MWM test determined that the memory of mice in the 2.6 and $1.3 \%$ sevoflurane groups were significantly weakened compared with that in the control group. These results provide evidence for sevoflurane-induced memory impairment in the developing brain of postnatal mice, suggesting that the use of sevoflurane during cesarean section may damage the brain development of postnatal infants. However, the time spent in the northwest quadrant and platform site crossovers was not significantly decreased by $2.6 \%$ sevoflurane exposure compared with that in the $1.3 \%$ sevoflurane group, apart from the platform site crossovers at the 12th week after sevoflurane exposure. Thus, there may not be a dose-dependent effect in sevoflurane-induced memory impairment for postnatal mice.

Consistent with previous studies $(8,9)$, caspase- 3 expression was significantly increased by sevoflurane in the present study. Furthermore, the results of the present study provided evidence for an association between caspase-3 and sevoflurane-induced memory impairment in postnatal mice. Meanwhile, levels of cleaved PARP in the 2.6 and $1.3 \%$ sevoflurane groups were significantly higher than that in the control group. It has been reported that the spatial memory of rats with twice-repeated cerebral ischemia could be significantly improved by decreasing levels of PARP and caspase-3 (34). Furthermore, increased expression of caspase- 3 and cleavage of PARP are associated with neuronal apoptosis in hippocampal tissue $(35,36)$, which is a major mechanism of memory impairment. Therefore, this evidence indicates that caspase- 3 induced cleavage of PARP may result in neuronal apoptosis in the hippocampus and lead to memory impairment in postnatal mice.

The expression of Akt/PKB and pro-BDNF in the hippocampal tissue was also significantly altered by $2.6 \%$ sevoflurane. It was reported that the cleavage of pro-BDNF is important in the formation of memories (37). The present study indicated that cleavage of pro-BDNF may be repressed by sevoflurane, leading to accumulation of pro-BDNF in the hippocampal tissue. Overall, pro-BDNF is cleaved and changed into BDNF, which is mediated by the activation of phosphatidylinositol 3-kinase (PI3K), in BDNF-dependent spatial memory formation (38). PI3K can then phosphorylate Akt/PKB. Inhibition of Akt phosphorylation exacerbates memory deficits in a rat model of Alzheimer's disease (39). 
Table III. Results of 6 days training in Morris water maze test.

A, Changes of time of escape latency at 4 th week (sec)

\begin{tabular}{|c|c|c|c|c|}
\hline Day & $2.6 \%$ sevoflurane group & $1.3 \%$ sevoflurane group & Control group & P-value ${ }^{c}$ \\
\hline 1 & $84.56 \pm 3.02$ & $73.94 \pm 4.98$ & $82.58 \pm 4.15$ & 0.396 \\
\hline 2 & $85.66 \pm 2.70$ & $74.98 \pm 4.85$ & $78.61 \pm 4.03$ & 0.269 \\
\hline 3 & $81.96 \pm 6.13$ & $71.88 \pm 6.45$ & $70.99 \pm 5.96$ & 0.233 \\
\hline 4 & $76.48 \pm 4.85^{\mathrm{a}}$ & $65.99 \pm 5.34^{\mathrm{a}}$ & $50.19 \pm 5.72$ & 0.003 \\
\hline 5 & $85.50 \pm 2.52^{\mathrm{a}, \mathrm{b}}$ & $67.22 \pm 4.89^{\mathrm{a}}$ & $45.55 \pm 4.87$ & $<0.001$ \\
\hline 6 & $69.17 \pm 5.56^{\mathrm{a}, \mathrm{b}}$ & $63.27 \pm 6.14^{\mathrm{a}}$ & $35.97 \pm 4.49$ & $<0.001$ \\
\hline P-value ${ }^{d}$ & 0.009 & $<0.001$ & $<0.001$ & \\
\hline
\end{tabular}

B, Changes of time of escape latency at 12 th week $(\mathrm{sec})$

\begin{tabular}{lccc}
\hline Day & 2.6\% sevoflurane group & $1.3 \%$ sevoflurane group & Control group $^{\text {P-value }}$ \\
\hline 1 & $81.68 \pm 3.58$ & $77.27 \pm 4.88$ & $72.61 \pm 5.29$ \\
2 & $71.96 \pm 4.98$ & $71.36 \pm 5.63$ & $69.71 \pm 6.12$ \\
3 & $54.40 \pm 5.19$ & $53.39 \pm 4.92$ & $67.75 \pm 5.16$ \\
4 & $55.23 \pm 5.48$ & $44.25 \pm 5.53$ & $60.81 \pm 5.59$ \\
5 & $53.23 \pm 5.84$ & $36.68 \pm 4.49$ & $42.09 \pm 5.42$ \\
6 & $52.42 \pm 5.46^{\mathrm{a}, \mathrm{b}}$ & $27.34 \pm 4.14$ & $32.73 \pm 5.12$ \\
P-value $^{\mathrm{d}}$ & $<0.001$ & $<0.001$ & $<0.001$ \\
\hline
\end{tabular}

${ }^{a} \mathrm{P}<0.05$ vs. the control using Student Newman-Keuls post hoc test, ${ }^{b} \mathrm{P}<0.05$ vs. the $1.3 \%$ sevoflurane group using Student Newman-Keuls post hoc test. ${ }^{c} \mathrm{P}$-value was calculated from $2.6 \%, 1.3 \%$ sevoflurane and control groups by the one-way analysis of variance method. ${ }^{\mathrm{d}} \mathrm{P}$-value was calculated from time of escape latency (days $1,2,3,4,5,6$ ) by a repeated measures analysis of variance. Data are presented as the mean \pm standard error of the mean. $n=10$.

Table IV. Time spent in the northwest quadrant and platform site crossovers in each group.

A, Results of the 4 th week

\begin{tabular}{|c|c|c|c|c|}
\hline Results of probe test & $2.6 \%$ sevoflurane group & $1.3 \%$ sevoflurane group & Control group & P-value \\
\hline $\begin{array}{l}\text { Time spent in the northwest } \\
\text { quadrant }(\mathrm{sec})\end{array}$ & $0.04 \pm 0.03^{\mathrm{a}}$ & $0.19 \pm 0.09^{\mathrm{a}}$ & $0.88 \pm 0.21$ & 0.001 \\
\hline Platform site crossovers (times) & $0.25 \pm 0.16^{\mathrm{a}}$ & $0.63 \pm 0.32^{\mathrm{a}}$ & $2.38 \pm 0.65$ & 0.003 \\
\hline
\end{tabular}

B, Results of the 12 th week

\begin{tabular}{|c|c|c|c|c|}
\hline Results of probe test & $2.6 \%$ sevoflurane group & $1.3 \%$ sevoflurane group & Control group & P-value ${ }^{c}$ \\
\hline $\begin{array}{l}\text { Time spent in the northwest } \\
\text { quadrant }(\mathrm{sec})\end{array}$ & $0.23 \pm 0.11^{\mathrm{a}}$ & $1.00 \pm 0.27^{\mathrm{a}}$ & $15.32 \pm 3.62$ & $<0.001$ \\
\hline Platform site crossovers (times) & $0.67 \pm 0.33^{\mathrm{a}, \mathrm{b}}$ & $2.63 \pm 0.71^{\mathrm{a}}$ & $4.67 \pm 1.18$ & 0.006 \\
\hline
\end{tabular}

${ }^{\mathrm{a}} \mathrm{P}<0.05$ vs. the control using a Student Newman-Keuls post hoc test. ${ }^{\mathrm{b}} \mathrm{P}<0.05$ vs. the $1.3 \%$ sevoflurane group using Student Newman-Keuls post hoc test. ${ }^{~} \mathrm{P}$-value was calculated from $2.6 \%, 1.3 \%$ sevoflurane and control groups by the one-way analysis of variance method. Results are presented as the mean \pm standard error of the mean. $n=10$.

Thus, activation of PI3K may be inhibited by sevoflurane and thereby decrease levels of phosphorylated Akt, as well as inhibit cleavage of pro-BDNF. Akt phosphorylation and activation of PI3K was not assessed in the present study, which is a limitation. However, it was speculated that the decrease in Akt levels observed in the present study was caused by the 
feedback inhibition of phosphorylated Akt. Further studies are required to consider the phosphorylation of Akt and the activation of PI3K in this potential mechanism.

In addition, the results also demonstrated that p75NTR was upregulated following sevoflurane exposure in postnatal mice. It has been reported that the pro-form of nerve growth factor (proNGF)-induced neuronal apoptosis is dependent on p75NTR in Alzheimer's disease (40). The balance of TrkA/p75NTR signaling is associated with (-)-epigallocatechin-3-gallate ameliorated learning and memory deficits in APP/PS1 transgenic mice (41). Furthermore, the balance of TrkA/p75NTR may be regulated by proNGF in the hippocampus (42). Thus, the balance of TrkA/p75NTR in the present study may be broken by sevoflurane, thereby impairing the ability of postnatal mice to form memories. ProNGF may serve a role in the sevoflurane-induced increase of p75NTR, promoting neuronal apoptosis and memory impairment. However, the effect of sevoflurane expression on TrkA and proNGF in postnatal mice is unknown. Further studies are required to investigate this effect systematically.

Additionally, it has been demonstrated that cleavage of pro-BDNF is essential for long-term hippocampal plasticity (38). Thus, the inhibition of pro-BDNF cleavage in mice exposed to sevoflurane may affect hippocampal plasticity in postnatal mice. Meanwhile, the increased expression of caspase-3 may induce neuronal apoptosis in the hippocampal tissue of postnatal mice in the present study. Thus, sevoflurane may discourage the plasticity of the hippocampus and promote neuronal apoptosis in a developing brain by inhibiting the cleavage of pro-BDNF and upregulating caspase- 3 in postnatal mice.

In the present study, hypoxia and respiratory depression were also evaluated in postnatal mice during sevoflurane exposure. The results identified that there were no significant differences among groups. However, in a previous study by Schlünzen et al (43), the mean $\mathrm{PaCO}_{2}$ and total CBF decreased, which may be induced by sevoflurane anesthesia and may cause hyperventilation. A limitation of the present study was the inability to confirm whether the sevoflurane anesthesia lead to hyperventilation. Further studies are required to investigate the hyperventilation caused by sevoflurane anesthesia.

In conclusion, the present study demonstrated that sevoflurane-induced memory impairment may be associated with neuronal apoptosis by inhibiting the cleavage of pro-BDNF, as well as increasing caspase-3 and p75NTR levels in the postnatal developing mouse brain.

\section{Acknowledgements}

The present study was supported by the Natural Science Foundation of Shanghai (grant no. 11ZR1423200)

\section{References}

1. Erden V, Erkalp K, Yangin Z, Delatioglu H, Kiroglu S, Ortaküz S and Ozdemir B: The effect of labor on sevoflurane requirements during cesarean delivery. Int J Obstet Anesth 20: 17-21, 2011.

2. Vora KS, Shah VR, Patel D, Modi MP and Parikh GP: Sevoflurane versus propofol in the induction and maintenance of anaesthesia in children with laryngeal mask airway. Sri Lanka J Child Health 43: 77-83, 2014.

3. Lerman J, Sikich N, Kleinman S and Yentis S: The pharmacology of sevoflurane in infants and children. Anesthesiology 80: 814-824, 1994
4. Liu F, Rainosek SW, Frisch-Daiello JL, Patterson TA, Paule MG, Slikker W Jr, Wang C and Han X: Potential adverse effects of prolonged sevoflurane exposure on developing monkey brain: From abnormal lipid metabolism to neuronal damage. Toxicol Sci 147: 562-572, 2015.

5. Tagawa T, Sakuraba S, Kimura K and Mizoguchi A: Sevoflurane in combination with propofol, not thiopental, induces a more robust neuroapoptosis than sevoflurane alone in the neonatal mouse brain. J Anesth 28: 815-820, 2014.

6. Zheng S, Chen X, Wang Y and An L: Effects of sevoflurane on brain neuroapoptosis and ability of long-term learning and memory in newborn rats. Beijing Da Xue Xue Bao 47: 674-678, 2015 (In Chinese).

7. Baydas G, Reiter R, Akbulut M, Tuzcu M and Tamer S: Melatonin inhibits neural apoptosis induced by homocysteine in hippocampus of rats via inhibition of cytochrome $\mathrm{c}$ translocation and caspase- 3 activation and by regulating pro-and anti-apoptotic protein levels. Neuroscience 135: 879-886, 2005.

8. Zhou X, Song FH, He W, Yang XY, Zhou ZB, Feng X and Zhou LH: Neonatal exposure to sevoflurane causes apoptosis and reduces nNOS protein expression in rat hippocampus. Mol Med Rep 6: 543-546, 2012.

9. Istaphanous GK, Howard J, Nan X, Hughes EA, McCann JC, McAuliffe JJ, Danzer SC and Loepke AW: Comparison of the neuroapoptotic properties of equipotent anesthetic concentrations of desflurane, isoflurane, or sevoflurane in neonatal mice. Anesthesiology 114: 578-587, 2011.

10. Albasser MM, Amin E, Lin TC, Iordanova MD and Aggleton JP: Evidence that the rat hippocampus has contrasting roles in object recognition memory and object recency memory. Behav Neurosci 126: 659-669, 2012.

11. Chambers RA, Potenza MN, Hoffman RE and Miranker W: Simulated apoptosis/neurogenesis regulates learning and memory capabilities of adaptive neural networks. Neuropsychopharmacology 29: 747-758, 2004.

12. Sung YJ and Ambron RT: PolyADP-ribose polymerase-1 (PARP-1) and the evolution of learning and memory. Bioessays 26: 1268-1271, 2004.

13. Cohen-Armon M, Visochek L, Katzoff A, Levitan D, Susswein AJ, Klein R, Valbrun M and Schwartz JH: Long-term memory requires polyADP-ribosylation. Science 304: 1820-1822, 2004.

14. Goldberg S, Visochek L, Giladi E, Gozes I and Cohen-Armon M: PolyADP-ribosylation is required for long-term memory formation in mammals. J Neurochem 111: 72-79, 2009.

15. Zhou B, Cai Q, Xie Y and Sheng ZH: Snapin recruits dynein to BDNF-TrkB signaling endosomes for retrograde axonal transport and is essential for dendrite growth of cortical neurons. Cell Rep 2: 42-51, 2012.

16. Stansfield KH, Pilsner JR, Lu Q, Wright RO and Guilarte TR: Dysregulation of BDNF-TrkB signaling in developing hippocampal neurons by $\mathrm{Pb}(2+)$ : Implications for an environmental basis of neurodevelopmental disorders. Toxicol Sci 127: 277-295, 2012.

17. Lai H, Zhao H, Zeng L and Lv Y: BDNF and TrkB mRNA expression in aged hippocampus neurons and their relationship with learning and memory. Prog Anatomical Sci 10: 353-356, 2004 (In Chinese).

18. Barrett GL, Reid CA, Tsafoulis C, Zhu W, Williams DA, Paolini AG, Trieu J and Murphy M: Enhanced spatial memory and hippocampal long-term potentiation in p75 neurotrophin receptor knockout mice. Hippocampus 20: 145-152, 2010.

19. Yao D, He X, Wang J and Zhao Z: Effects of PI3K/Akt signaling pathway on learning and memory abilities in neonatal rats with hypoxic-ischemic brain damage. Zhongguo Dang Dai Er Ke Za Zhi 13: 424-427, 2011 (In Chinese).

20. Zhang JF, Zhou W and Wang T: Effects of propofol on studying and memory dysfunction and cortex trkb/akt pathway in focal cerebral ischemia/reperfusion injury of rats. Herald Med 2: 008, 2012 (In Chinese).

21. Sadrian B, Subbanna S, Wilson DA, Basavarajappa B and Saito M: Lithium prevents long-term neural and behavioral pathology induced by early alcohol exposure. Neuroscience 206: 122-135, 2012.

22. National Research Council: Guide for the Care and Use of Laboratory Animals. National Academies Press, Washington, DC, pp1072-1073, 2011.

23. Wiklund A, Granon S, Faure P, Sundman E, Changeux JP and Eriksson LI: Object memory in young and aged mice after sevoflurane anaesthesia. Neuroreport 20: 1419-1423, 2009. 
24. Yue T, Shanbin G, Ling M, Yuan W, Ying X and Ping Z: Sevoflurane aggregates cognitive dysfunction and hippocampal oxidative stress induced by $\beta$-amyloid in rats. Life Sci 143: 194-201, 2015

25. Zhang F, Feng X, Zeng Q, Wang B, Wilhelmsen K, Li Q, Cao X and Yu B: Sevoflurane induced amnesia inhibits hippocampal Arc expression partially through 5-hydroxytryptamine-7 receptors in the bilateral basolateral amygdala in rats. Neurosci Lett 562: 13-18, 2014

26. Zhong T, Guo Q, Zou W, Zhu X, Song Z, Sun B, He X and Yang Y: Neonatal isoflurane exposure induces neurocognitive impairment and abnormal hippocampal histone acetylation in mice. Plos One 10: e0125815, 2015.

27. Musumeci G, Castrogiovanni P, Loreto C, Castorina S, Pichler K and Weinberg AM: Post-traumatic caspase-3 expression in the adjacent areas of growth plate injury site: A morphological study. Int J Mol Sci 14: 15767-15784, 2013.

28. Ge HW, Hu WW, Ma LL and Kong FJ: Endoplasmic reticulum stress pathway mediates isoflurane-induced neuroapoptosis and cognitive impairments in aged rats. Physiol Behav 151: 16-23, 2015

29. Lin D and Zuo Z: Isoflurane induces hippocampal cell injury and cognitive impairments in adult rats. Neuropharmacology 61 : 1354-1359, 2011.

30. Cao J, Wang Z, Mi W and Zuo Z: Isoflurane unveils a critical role of glutamate transporter type 3 in regulating hippocampal GluR1 trafficking and context-related learning and memory in mice. Neuroscience 272: 58-64, 2014.

31. Li XM, Su F, Ji MH, Zhang GF, Qiu LL, Jia M, Gao J, Xie Z and Yang JJ: Disruption of hippocampal neuregulin 1-ErbB4 signaling contributes to the hippocampus-dependent cognitive impairment induced by isoflurane in aged mice. Anesthesiology 121: 79-88, 2014.

32. Cao Y, Ni C, Li Z, Li L, Liu Y, Wang C, Zhong Y, Cui D and Guo X: Isoflurane anesthesia results in reversible ultrastructure and occludin tight junction protein expression changes in hippocampal blood-brain barrier in aged rats. Neurosci Lett 587: 51-56, 2015.

33. Li Z, Cao Y, Li L, Liang Y, Tian X, Mo N, Liu Y, Li M, Chui D and Guo X: Prophylactic angiotensin type 1 receptor antagonism confers neuroprotection in an aged rat model of postoperative cognitive dysfunction. Biochem Biophys Res Commun 449: 74-80, 2014.

34. Hatip-Al-Khatib I, Iwasaki K, Chung EH, Egashira N, Mishima K and Fujiwara M: Inhibition of poly (ADP-ribose) polymerase and caspase-3, but not caspase-1, prevents apoptosis and improves spatial memory of rats with twice-repeated cerebral ischemia. Life Sci 75: 1967-1978, 2004.
35. Comim CM, Barichello T, Grandgirard D, Dal-Pizzol F, Quevedo J and Leib SL: Caspase-3 mediates in part hippocampal apoptosis in sepsis. Mol Neurobiol 47: 394-398, 2013.

36. Gerace E, Masi A, Resta F, Felici R, Landucci E, Mello T, Pellegrini-Giampietro DE, Mannaioni G and Moroni F: PARP-1 activation causes neuronal death in the hippocampal CA1 region by increasing the expression of $\mathrm{Ca}(2+)$-permeable AMPA receptors. Neurobiol Dis 70: 43-52, 2014.

37. Barnes P and Thomas KL: Proteolysis of proBDNF is a key regulator in the formation of memory. PLoS One 3: e3248, 2008.

38. Mizuno M, Yamada K, Takei N, Tran MH, He J, Nakajima A, Nawa $\mathrm{H}$ and Nabeshima T: Phosphatidylinositol 3-kinase: A molecule mediating BDNF-dependent spatial memory formation. Mol Psychiatry 8: 217-224, 2003.

39. Shaerzadeh F, Motamedi F and Khodagholi F: Inhibition of akt phosphorylation diminishes mitochondrial biogenesis regulators, tricarboxylic acid cycle activity and exacerbates recognition memory deficit in rat model of Alzheimer's disease. Cell Mol Neurobiol 34: 1223-1233, 2014

40. Pedraza CE, Podlesniy P, Vidal N, Arévalo JC,Lee R, Hempstead B, Ferrer I, Iglesias $\mathrm{M}$ and Espinet C: Pro-NGF isolated from the human brain affected by Alzheimer's disease induces neuronal apoptosis mediated by p75NTR. Am J Pathol 166: 533-543, 2005.

41. Liu M, Chen F, Sha L, Wang S, Tao L, Yao L, He M, Yao Z, Liu H, Zhu Z, et al: (-)-Epigallocatechin-3-gallate ameliorates learning and memory deficits by adjusting the balance of TrkA/p75NTR signaling in APP/PS1 transgenic mice. Mol Neurobiol 49: 1350-1363, 2014

42. Fortress AM, Buhusi M, Helke KL and Granholm AC: Cholinergic degeneration and alterations in the TrkA and p75NTR balance as a result of pro-NGF injection into aged rats. J Aging Res 2011: 460543, 2011.

43. Schlünzen L, Vafaee M, Juul N and Cold G: Regional cerebral blood flow responses to hyperventilation during sevoflurane anaesthesia studied with PET. Acta Anaesthesiol Scand 54: 610-615, 2010.

This work is licensed under a Creative Commons

Attribution-NonCommercial-NoDerivatives 4.0 International (CC BY-NC-ND 4.0) License. 